\title{
Emergence of tick-borne encephalitis in new endemic areas in Austria: 42 years of surveillance
}

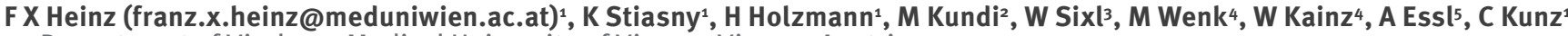

1. Department of Virology, Medical University of Vienna, Vienna, Austria

2. Institute of Environmental Health, Medical University of Vienna, Vienna, Austria

3. Institute of Hygiene, University of Graz, Graz, Austria

4. Department of Geography and Regional Research, University of Vienna, Vienna, Austria

5. GfK Austria HealthCare, Vienna, Austria

Citation style for this article:

Heinz FX, Stiasny K, Holzmann H, Kundi M, Sixl W, Wenk M, Kainz W, Essl A, Kunz C. Emergence of tick-borne encephalitis in new endemic areas in Austria: 42 years of surveillance. Euro Surveill. 2015;20(13):pii=21077. Available online: http://www.eurosurveillance.org/ViewArticle.aspx?Articleld=21077

Human infections with tick-borne encephalitis (TBE) virus are a public health concern in certain regions of Europe, central and eastern Asia. Expansions of endemic areas and increased incidences have been associated with different factors including ecological changes supporting tick reproduction, socioeconomic changes increasing human outdoor activities and climatic changes favouring virus circulation in natural foci. Austria is among the most strongly affected countries in Central Europe, but the annual number of cases has strongly declined due to vaccination. Here, we have analysed changes of the incidence of TBE in the unvaccinated population of all federal states of Austria over a period of 42 years. The overall incidence in Austria has remained constant, but new strongly affected endemic regions have emerged in alpine valleys in the west of Austria. In parallel, the incidence in low-land regions in the north-east of the country is decreasing. There is no evidence for a shift to higher altitudes of infection sites in the traditional TBE zones, but the average altitudes of some newly established endemic areas in the west are significantly higher. Our analyses underscore the focal nature of TBE endemic areas and the potential of TBE virus to emerge in previously unaffected regions.

\section{Introduction}

Tick-borne encephalitis (TBE) virus is endemic in many parts of Europe as well as central and eastern Asia and responsible for more than 10,000 hospitalised TBE patients every year [1]. Together with the mosquito-transmitted yellow fever, dengue, West Nile and Japanese encephalitis viruses it is a member of the genus Flavivirus in the family Flaviviridae and consists of at least three antigenically closely related subtypes [2]. The European subtype is primarily transmitted by Ixodes ricinus, whereas Ixodes persulcatus is the main vector of the Siberian and Far Eastern subtypes [3]. In the Baltic countries and Finland, an overlap of vectors and subtypes has been described [4,5]. The human disease can be effectively prevented by vaccination with formalin-inactivated vaccines, as demonstrated by epidemiological studies in countries and regions with high vaccination coverage, such as Austria or the Sverdlovsk district in Russia $[6,7]$.

The ecological conditions for maintaining TBE virus replication and persistence in nature are very complex and fragile. They require not only the availability of specific animal hosts (rodents and larger mammals such as roe deer) for feeding the different stages of tick development (larvae, nymphs and adults) and increasing their density, but also favourable conditions for the transmission of the virus between different developmental stages. There is strong evidence that conditions allowing non-viraemic transmission from infected larvae to non-infected nymphs by co-feeding on the same rodent are a major prerequisite for the maintenance of virus circulation in nature [8]. Such a mechanism of tick infection requires specific climatic conditions (especially a swift rise of temperature in spring) that lead to a temporal coincidence of larval and nymph development and possibly contribute to the restriction of TBE virus to selected endemic regions. This is in contrast to other tick-transmitted pathogens such as Borrelia burgdorferi that are found in all areas populated with ticks [9-12].

Strong annual variations as well as long fluctuations over time are a characteristic feature of the TBE incidence in affected countries $[6,13,14]$ and an overall upsurge has been reported in certain parts of Europe (reviewed in [15]). These changes have been related to climatic, ecological, environmental and socioeconomic factors that can lead to an increased risk of human exposure to infected ticks [8,16-19]. In addition, however, the establishment of new natural foci of TBE virus circulation has been described in areas previously considered free of TBE, as for instance in certain parts of Norway [20], Sweden [21,22], Finland [23], Denmark 
Incidence rates of tick-borne encephalitis in Austria (total and unvaccinated population) and its federal states (unvaccinated population), 1972-2013

A
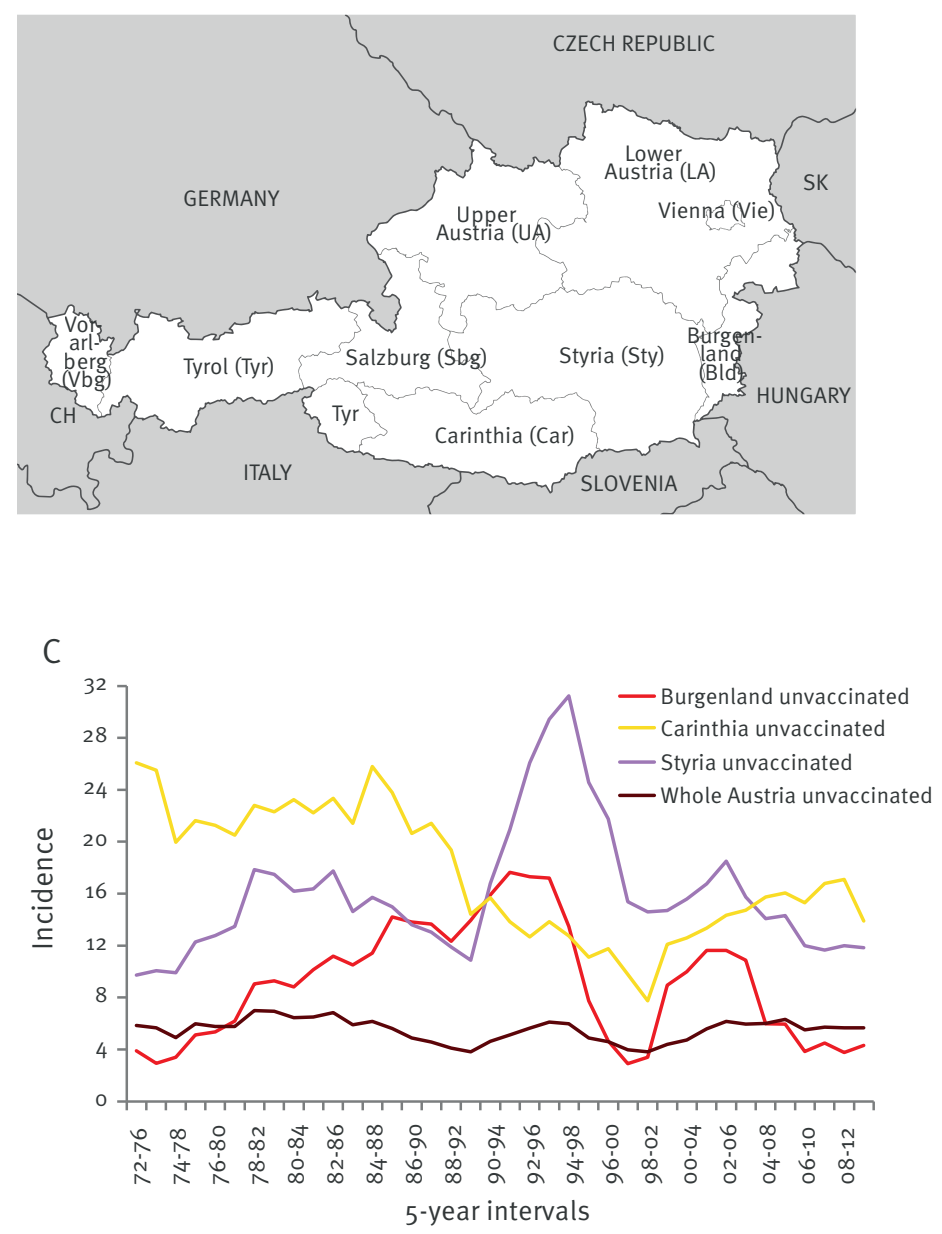

B

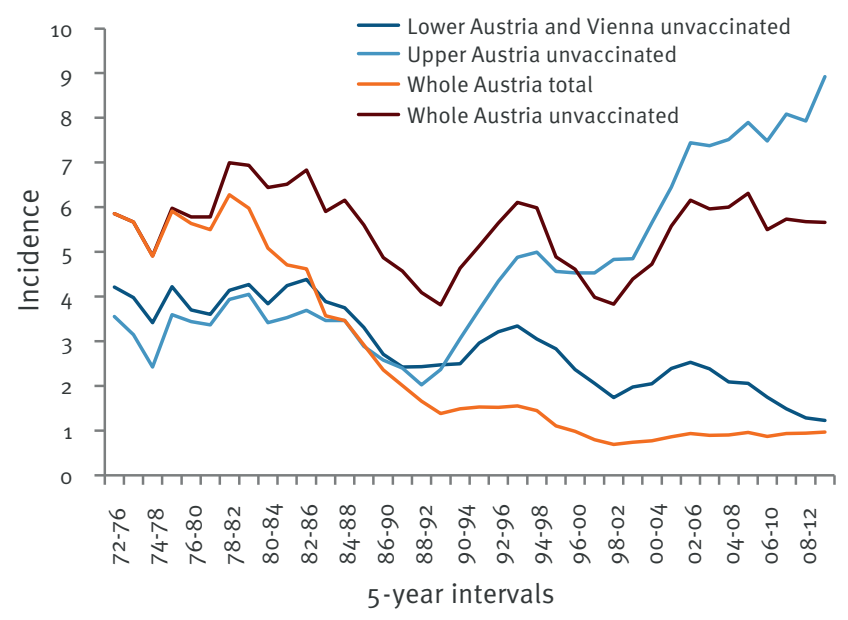

D

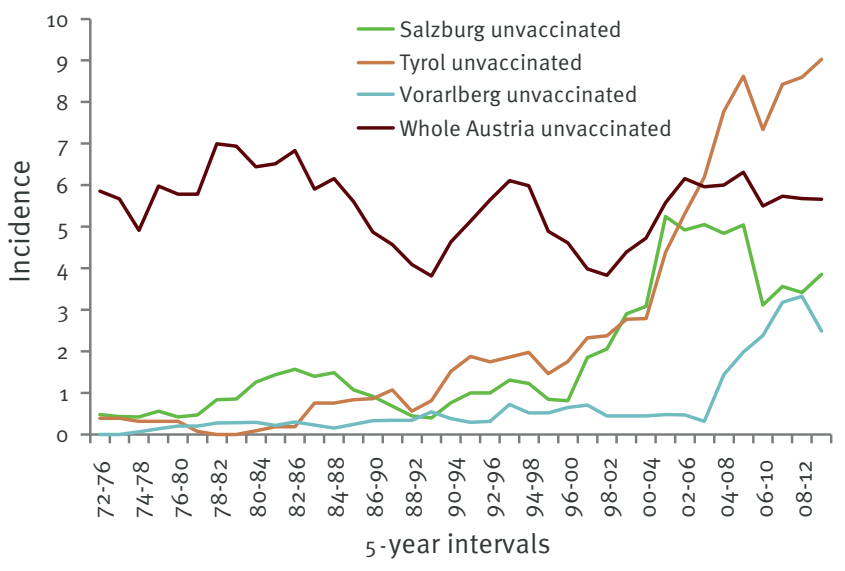

CH: Switzerland; SK: Slovakia.

Incidence: Number of cases/100,000 population. Assignment to federal states is based on the site of hospitalisation.

[24] and Switzerland [13,25] as well as areas of higher altitude in the Czech Republic $[19,26]$ and Slovakia [27]. The mechanisms underlying the discontinuous spread of the virus and its long-distance transport to previously unaffected areas are largely unknown but may be related to (i) changes in climatic conditions that allow virus maintenance in natural hosts and (ii) birds [2830] or larger mammals (including humans) serving as transport vehicles of infected ticks $[21,31]$.

In Austria, the high vaccination coverage (more than $80 \%$ of the total population has received at least one TBE vaccination) has led to a substantial decline in the number of annual cases [6]. The incidence in the unvaccinated population, however, is virtually identical with that in the prevaccination era (on average ca 6 per 100,000 in the whole country), indicating that the overall risk of human exposure to TBE virus has remained constant [6]. In this work, we have addressed the question of possible regional changes of TBE endemicity by analysing the incidences of TBE in the unvaccinated population over a period of 42 years (1972 to 2013) in all federal states of Austria. Since the documentation of cases based on administrative districts blurs the situation of real risk areas, we also mapped the cases over the whole time period based on questionnaires indicating the most likely site of infection.

\section{Methods}

Documentation of tick-borne encephalitis cases Data on TBE cases were documented by the Department of Virology, Medical University of Vienna, acting as the National Reference Laboratory for TBE virus and other flavivirus infections, on the basis of confirmed laboratory diagnosis of each case and on the basis of questionnaires. Only hospitalised patients with a serologically confirmed recent infection with TBE virus were counted as cases. Confirmation was based on TBE virus IgM and IgG ELISA results, which have replaced 
the haemagglutination inhibition and/or complement fixation assays used until the early 1980 s in Austria.

Each confirmed case received a questionnaire to provide information on tick bites and possible sites of infection. Since only ca $50 \%$ of the patients had a known history of a tick bite, the time elapsed between infection and hospitalisation is usually three to four weeks and the origin of the infecting tick can be uncertain, the geographical mapping of infection sites was based on a subset of patients (ca $36 \%$ of the total cases) who could provide data precise enough to make the site of infection 'most likely'.

\section{Calculation of incidence rates}

Overall incidence rates and incidence rates in unvaccinated persons were calculated for the Austrian federal states individually (because of its location, the capital state of Vienna was included in the counts of Lower Austria; Figure 1A) and for the whole of Austria, using population data from Statistics Austria [37] and data on vaccination status in each federal state collected by GfK Austria HealthCare (Vienna, Austria) through postal surveys [6]. Data on possible regional differences in vaccination coverages within federal states were not available. As described previously [6], the incidence among unvaccinated persons was estimated by assuming a vaccine efficacy of $97 \%$ for the years before 2000 [6]; since 2000 , the actual number of cases that occurred among unvaccinated persons has been used for calculation. The assignment of cases to individual federal states was based on the site of hospitalisation.

\section{Mapping of infection sites by ArcGIS}

Infection sites were geocoded and further processed for spatial mapping by ArcGIS (Environmental Systems Research Institute; ESRI Inc.). Spatially close sites were aggregated to a single point using a $1 \mathrm{~km}$ buffer around the individual points, assembling the union of all buffers, and subsequently calculating the centroid of the area. For the display of aggregated infection sites in the maps, these centroids formed the centre of circles with diameters proportional to the number of infection sites found within this area.

For building the base map of Austria (Figure 2), we used data of Statistics Austria (http://www.statistik. at/web_de/services/geodaten/) for borders of Austria and its federal states, Natural Earth Data (http://www. naturalearthdata.com/downloads/10m-physical-vectors/) for rivers, lakes and cities, and Aster data of the United States Geological Survey (USGS; http://earthexplorer.usgs.gov/) for topography.

Altitudes of infection sites were derived from the digital elevation model (DEM) of USGS Aster data (spatial resolution of $30 \mathrm{~m}$ ), using the original coordinates for each single documented 'most likely' infection site.
Statistical analyses of altitudes of infection sites Sea level data of infection sites were log-transformed due to the skewed distribution. Normal distribution of residuals of the transformed data was tested by Kolmogorov-Smirnov test with Lilliefors' corrected $p$ values. A two-factor analysis of variance of transformed sea level data with period (1972-1983, 1984-2013) and region (six affected federal states in 1972-1983 and eight in 1984-2013) as factors was performed. Comparison of periods within regions was done by linear contrasts. Differences in the scatter of altitudes were tested by Levene's test for homogeneity. Due to the fact that no cases occurred in Tyrol and Vorarlberg during the first period, differences between regions were tested separately for the two periods with one-way analyses of variance. Pairwise differences between regions were tested by Tukey's honest significant difference (HSD) test for unequal sample size.

\section{Results}

\section{Changes in the incidence of tick-borne} encephalitis in Austria

In the past two to three decades, the most remarkable change in TBE incidence in Austria was caused by vaccination, resulting in an $84 \%$ reduction of the annual number of cases, while the incidence in the unvaccinated population remained constant at ca 6 per 100,000 population [6]. On the background of this unaltered overall risk of TBE virus infection in Austria, we wanted to assess possible regional shifts and dynamics of endemic areas. For this purpose, we determined the incidence rate in the unvaccinated population for the whole of Austria and each of the Austrian federal states (Figure $1 \mathrm{~A}$ ) and assuming a vaccine protection rate of $97 \%$ [6]. To reveal long-range developments and to avoid confusion due to the strong annual fluctuations typical of TBE $[6,13,14]$, we used a sliding window representation of the mean incidences in five year intervals. The overall situation in Austria (including the incidence in the unvaccinated population) is displayed in Figure $1 \mathrm{~B}$.

Disparate developments occurred in the northern states of Upper and Lower Austria (including the capital state of Vienna) which border Germany, the Czech Republic and Slovakia (Figure 1B). Both of these regions started with an incidence of ca 4 (Lower Austria/Vienna: 4.2; Upper Austria: 3.6) per 100,000 at the beginning of the observation period, but after 1990, the incidence in Upper Austria began to rise and reached 8.9 per 100,000 in the period 2009 - 2013. In contrast, in Lower Austria/Vienna, the incidence continuously declined to 1.2 per 100,000 (Figure 1B).

Figure $1 \mathrm{C}$ shows the development in the most strongly affected areas in the south of Austria, including the federal states of Carinthia, Styria and Burgenland at the borders to Italy/Slovenia, Slovenia and Hungary, respectively (Figure $1 \mathrm{~A}$ ). All three states had substantially higher mean incidences than the whole of Austria 


\section{FIGURE 2}

Sites of tick-borne encephalitis virus infection, Austria, 1972-2013

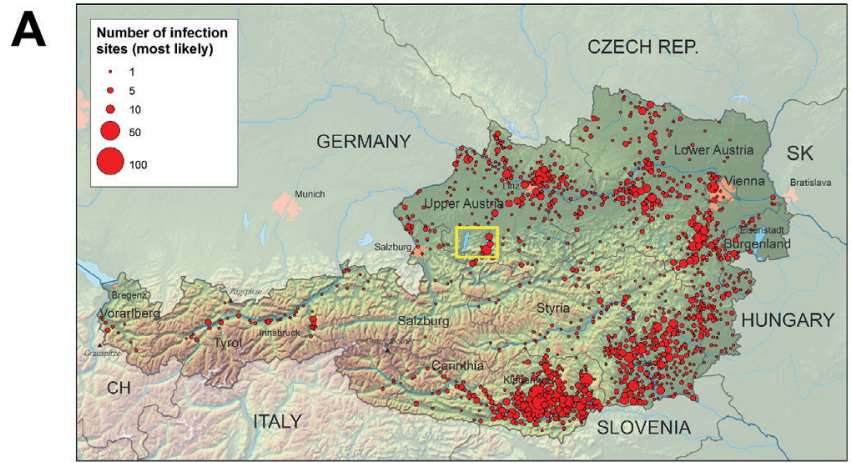

B

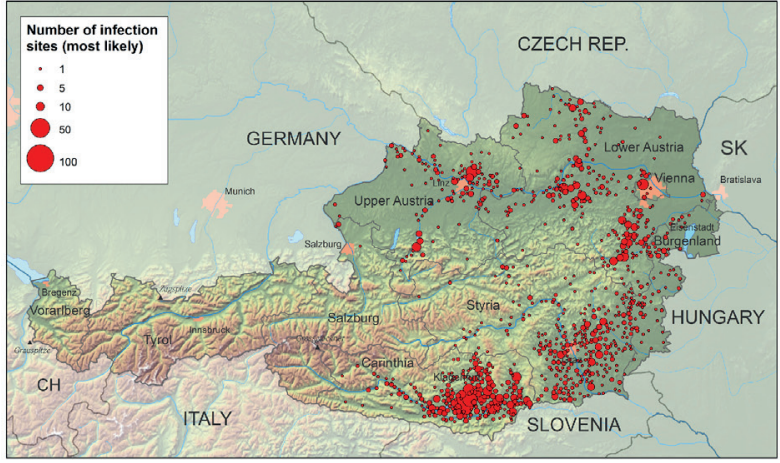

C

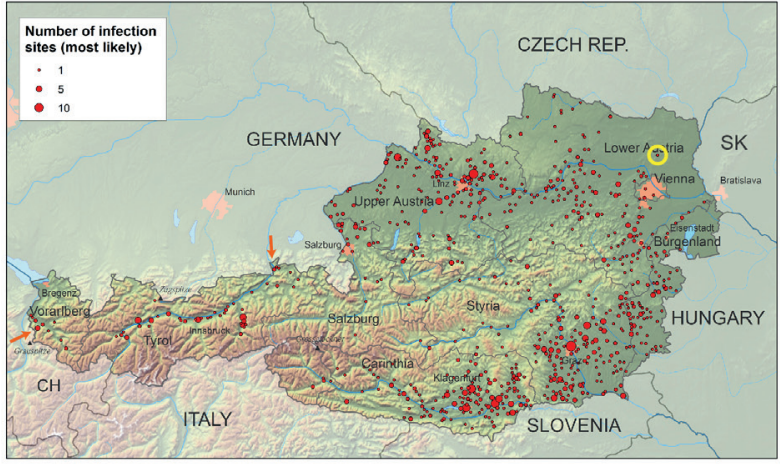

$25 \quad 50 \quad 100 \quad 150 \quad 200$ kilimeles

A. Cumulative data for the whole period 1972 to 2013

B. Data from 1972 to 1983

C. Data from 1984 to 2013

CH: Switzerland; SK: Slovakia.

The size of the red circles is proportional to the number of documented infection sites within this area (see insert). (A) Yellow rectangle indicates the lake district east of Salzburg. (B) Yellow circle indicates last 'most likely' infection site in northeast Lower Austria in 1984. Orange arrows indicate possible sites of virus seeding into new endemic areas through valleys.

during the entire observation period (17.9/100,000 in Carinthia, 15.4/100,000 in Styria, and 8.6/100,000 in Burgenland) and displayed strong annual fluctuations of minimum and maximum incidences, ranging from 1.2 to 42.8 per 100,000 in Carinthia, 5.5 to 42.6 per 100,000 in Styria, and o to 32.6 per 100,000 in Burgenland. Importantly, the fluctuations were not synchronised in the three states, suggesting strong region-specific differences in the activity of natural foci and other factors potentially influencing the risk of human exposure to TBE virus.

The most striking changes were observed in the alpine regions in the west of Austria, including the states of Salzburg, Tyrol, and Vorarlberg (Figure 1D). Both Salzburg and Tyrol experienced strong increases in incidence around 2000 which later levelled off in Salzburg but continued to rise in Tyrol and reached more than 8 per 100,000 , i.e. well above the Austrian average. In 2013, the incidence in Tyrol was almost as high as in the most strongly affected state Carinthia (13.9 vs 15.1 per 100,000) and higher than in Styria (11.3 per 100,000). In the western-most state Vorarlberg, a similar steep rise began ca 10 years later and appears to continue.

\section{Changes in infection sites in Austria}

Although the documentation of TBE cases according to hospitalisation in administrative regions such as the federal states provides good information about trends of shifting incidences of disease in different areas of the country, it is imprecise with respect to the true location of infection sites. To obtain a more detailed picture of risk areas, we evaluated the information provided through questionnaires received by the national reference laboratory for TBE in Austria. Considering the time elapsed between infection and hospitalisation and the inherent uncertainty of the origin of the tick leading to infection, we used very stringent criteria for the mapping of new infection sites. Figure 2 therefore contains only data from cases for whom other possible sites of infection could be excluded with high probability. One also needs to keep in mind that the total number of cases in Austria, and concomitantly the sampling of infection sites, has strongly declined over time due to vaccination (Figure 1B). Quantitative inferences can thus not be made from Figure 2 with respect to the prevalence of TBE virus and the total number of bites by infected ticks. The data are displayed for the complete observation period (1972-2013; Figure 2A) and for two time windows separately: 1972 to 1983 (the period before the first documentation of an autochthonous case in Tyrol in 1984; Figure 2B) and 1984 to 2013 (Figure 2C). A total of 5,148 and 3,495 cases were recorded from 1972 to 1983 and from 1984 to 2013, respectively. Over the whole time period, a 'most likely' site of infection could be identified for ca $36 \%$ of these cases.

The most striking changes in infection sites occurred in the alpine regions in the west of Austria, affecting especially Tyrol and Vorarlberg where no TBE was reported before 1984 and 2000, respectively. Since then, TBE has become highly endemic in the valleys of the rivers Inn and Ziller (Tyrol) and that of the river IIl (Walgau, Vorarlberg) (Figure 2C). First cases of TBE have also been documented since 2000 in another alpine valley (Salzach River) south of the city of Salzburg (Figure $2 \mathrm{C}$ ). Further comparison of the maps 
Altitudes of tick-borne encephalitis infection sites, Austria, 1972-1983 compared with 1984-2013

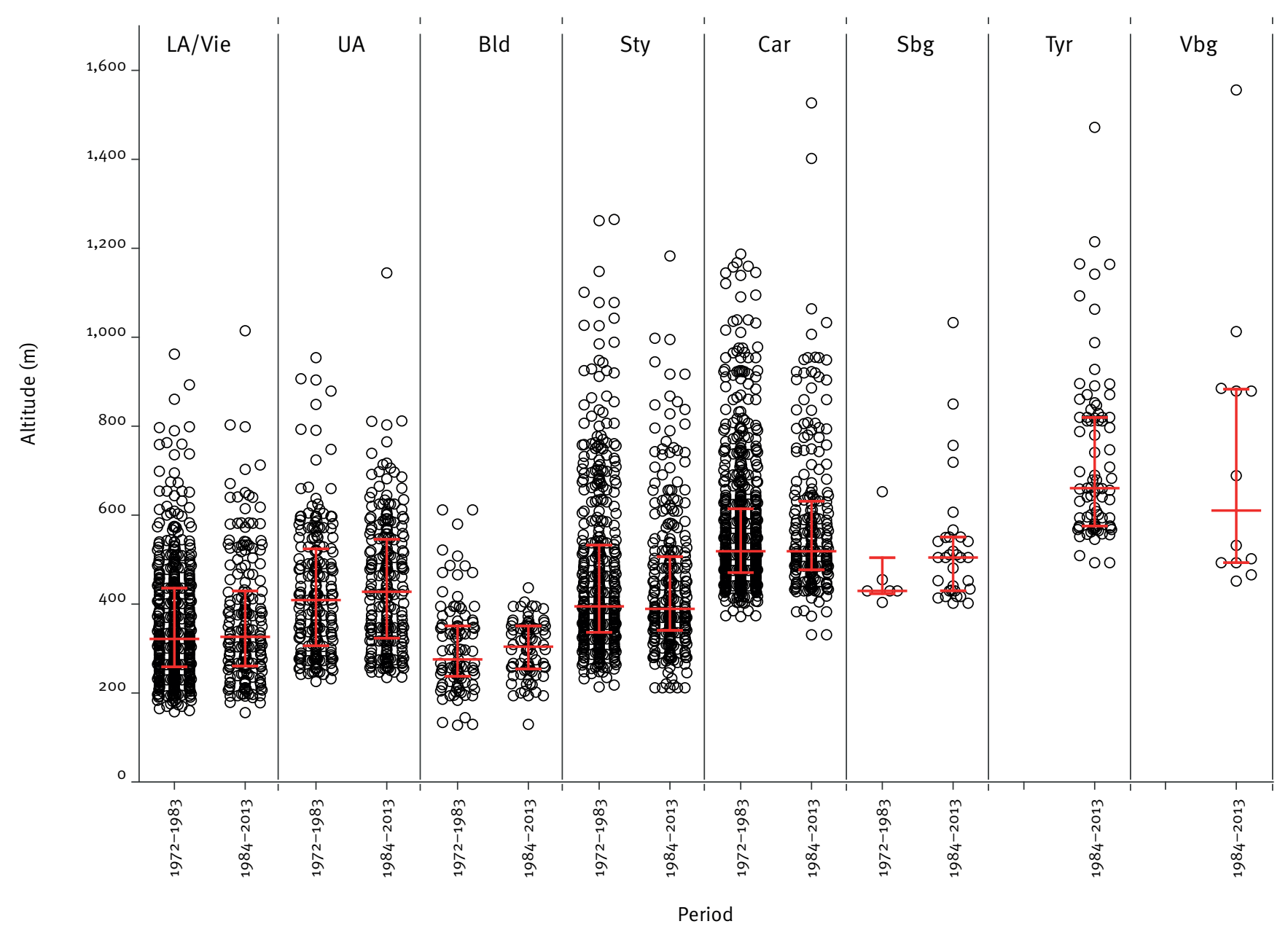

Bld: Burgenland; Car: Carinthia; LA/Vie: Lower Austria and Vienna; Sbg: Salzburg; Sty: Styria; Tyr: Tyrol; UA: Upper Austria; Vbg: Vorarlberg. Each circle represents a documented 'most likely' infection site. Error bars represent the medians and interquartile ranges.

also suggests the establishment of new endemic foci or at least increasing TBE activity in a region North of Salzburg (Figure $2 \mathrm{C}$ ). The opposite effect, i.e. decreasing activity or complete disappearance, however, can be inferred from the comparison of the situation in the north-east of Lower Austria (Figure 2C) where the last 'most likely' infection site was recorded in 1984 (Figure $2 \mathrm{C}$; yellow circle).

\section{Altitudes of infection sites}

Since the geographically most remarkable areas of TBE emergence were located in alpine regions of western Austria and data from other countries such as the Czech Republic $[19,26]$ and Slovakia [27] suggest a rise of TBE foci at higher altitudes, we analysed the sea levels of all mapped sites of TBE infections in Austria and determined their distribution in the federal states in the time periods 1972 to 1983 and 1984 to 2013 (Figure 3). In accordance with the topography of Austria, the average altitudes of infection sites differed between individual federal states and range from $300 \mathrm{~m}$ in Burgenland to $730 \mathrm{~m}$ in Tyrol. For the traditional endemic areas, possible shifts to higher altitudes were evaluated by comparing the two time windows (1972-1983 and 1984-2013) using analysis of variance with linear contrasts for each region. No statistically significant difference was observed at the level of federal states, neither with respect to the average altitudes ( $p$ values between 0.154 and 0.705 ) nor the scattering of altitudes in individual states ( $p$ value: 0.272). Nevertheless, individual infection sites at altitudes around $1,500 \mathrm{~m}$ were only found in the later time window of 1984 to 2013 (two in Carinthia, one in Tyrol, one in Vorarlberg) (Figure 3). The new infection sites in Tyrol, however, proved to be significantly higher than those in the rest of the country (Table). Because of the relatively low number of cases and the strong scattering of altitudes, statistical significance was not reached in the comparisons of Vorarlberg with Tyrol, Salzburg and Carinthia (Table). 
Pairwise comparisons of sea levels of tick-borne encephalitis virus infection sites between federal states of Austria, $1972-2013$

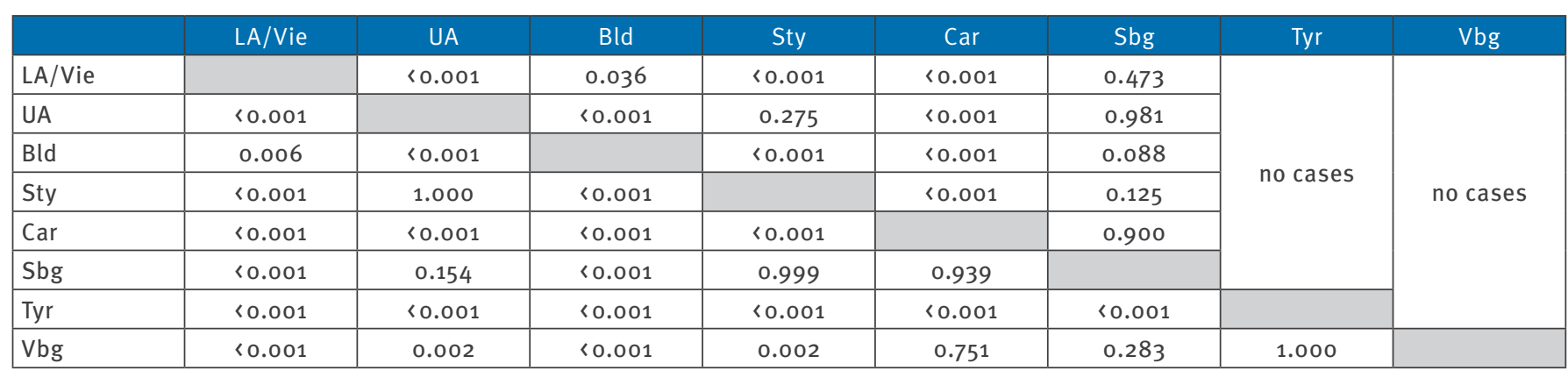

Bld: Burgenland; Car: Carinthia; LA/Vie: Lower Austria and Vienna; Sbg: Salzburg; Sty: Styria; Tyr: Tyrol; UA: Upper Austria; Vbg: Vorarlberg. p values form Tukey's HSD test. Upper triangular matrix: period 1972-1983; lower triangular matrix: period 1983-2013.

\section{Discussion}

We have evaluated epidemiological changes of TBE in Austria over an observation period of more than 40 years at a regional level. A number of factors have been described that can affect the documented incidence of TBE. These include climatic or anthropogenic environmental changes influencing the ecosystems required for virus circulation in nature [8], socioeconomic changes increasing the risk of human exposure to tick bites [16], changes in the awareness, laboratory diagnosis and notification of the disease, as well as vaccination [6]. In Austria, a marked decline of TBE incidence was concomitant with a steadily increasing vaccination coverage, which started in the late $1970 \mathrm{~s}$ and reached more than $80 \%$ of the total population around 2000 [6]. The incidence in the unvaccinated population, however, remained constant at ca 6 per 100,000 (Figure $1 \mathrm{~B}$ ), suggesting no major changes in the countrywide overall risk of human exposure to TBE virus-infected ticks. It is, however, apparent from our analysis of incidences in the unvaccinated population in the different federal states as well as the mapping of sites of infection, that this figure is an aggregate of opposing trends in different parts of the country, with increasing incidences in alpine regions in the west, decreasing incidences in the north-east and relative constancy in the high endemic areas in the south.

The development of new endemic regions in Tyrol (first documented case in 1984) and Vorarlberg (first documented case in 2000) deserves special attention. Since there is no evidence for socioeconomic or behavioural changes on such a small regional and temporal scale that might have increased the risk of exposure, the changes can best be explained by the establishment of truly novel natural foci and their further spread to cover large parts of the valleys of the rivers Inn and Ziller in Tyrol and the river III in Vorarlberg. A very similar expansion of TBE virus into a mountain valley also occurred recently in the Canton Valais in Switzerland [25,32], suggesting that similar mechanisms operate in alpine regions of Central Europe that allow the dispersion of this virus. It remains an unresolved issue, however, how the virus could have reached these locations. They are separated from other endemic regions by high mountain barriers, raising the possibility that the seeding with the virus occurred through the courses of rivers and valleys, e.g. from southern Germany to Tyrol through the Inn valley and from the Rhine valley in Liechtenstein/eastern Switzerland to Vorarlberg (Figure 2C). In this context, it is important to note that in the Austrian examples, both sides of the valleys became affected, i.e. the river did not represent a barrier in the establishment and spread of the virus. An extension of endemic areas along rivers would be consistent with recent phylogenetic analyses of virus isolates from Germany, the Czech Republic and Slovakia [33], which unveiled a predilection of long-distance migratory routes of TBE virus along river valleys in the past 300 years. Similar studies have not yet been conducted for Austria. Comparative analyses of the sequences of virus isolates from different parts of Austria and other European countries could shed light on the viral origins of the new endemic areas. Roe deer have been implicated in long-distance transport of infected ticks [33] but introduction by birds is also a possibility $[28,29]$. It cannot be excluded that the potential ways of virus dispersal in Europe have changed over time, but it appears more likely that the emergence of new endemic regions is caused by the establishment of previously non-existing suitable climatic and ecological conditions that are required for the maintenance of TBE virus circulation in nature [34].

Similar to the decreased incidence of TBE in Hungary (ca 2.8/100,000 until 1997 and 0.4 to 0.8 thereafter [35], although vaccination coverage was very low [36], the north-east of Austria (including the capital city of Vienna and some of its most popular recreational areas) also encountered a decline from an incidence of ca 4 to only ca1.3 per 100,000 (Figure $1 \mathrm{C}$ ). In the absence of evidence for human behavioural changes at such a 
small regional level and other factors that could affect TBE virus endemicity, these data suggest decreasing virus activity and even the loss of natural foci in these regions. Most of these areas have an altitude below $400 \mathrm{~m}$, in contrast to those with increasing incidences in western Austria, with median altitudes of more than $600 \mathrm{~m}$ (Figure 3). A similar trend, i.e. reduction of cases in lowlands and increases in submountaineous areas has also been described in Slovakia [27] and may be associated with climatic changes that are unfavourable for the maintenance of virus circulation in its natural hosts in the lowland areas of these countries. With respect to the average overall altitudes of infection sites, however, no significant changes were observed over the whole period of observation in the traditional endemic areas in Austria (Figure 3), similar to the situation in the Czech republic [19].

Overall, our data document strong region-specific differences in the changing epidemiology of TBE and conform to a tendency of establishment of new natural foci of TBE in Europe. This has been observed on a wide geographical scale and includes countries with different climates and topographies such as Norway, Sweden, Finland, Denmark, and Switzerland [13,20-25]. The mechanisms of establishment as well as spread and the factors controlling these processes, however, are still far from clear. This may be exemplified by the situation in the lake district east of Salzburg. Here, the virus is highly endemic in certain locations but several lakes and intervening hill sides are completely spared (Figure 2A) and not a single case has been documented in the 42 years of observation, although all known parameters potentially affecting TBE virus circulation and human infection (climate, landscape and geography, human outdoor activities, animal reservoirs etc.) are seemingly identical in the whole region. The elucidation of the interplay of processes driving or restricting the spread of TBE virus and, consequently, a detailed understanding of the focal nature of TBE endemic areas remain a formidable challenge for the future.

\section{Acknowledgements}

We thank Cornelia Stoeckl, Jutta Hutecek and Silvia Schwoediauer for expert technical assistance as well as the Institute of Hygiene, Medical University of Graz, and the Institute of Hygiene (now Section Virology), Medical University of Innsbruck, for help in data collection. The study was supported by intramural funds of the Medical University of Vienna, Vienna, Austria. The collection of data on regional distribution and vaccination coverage was supported by Baxter AG, Vienna, Austria.

\section{Conflict of interest}

None declared.
Authors' contributions

Study design, data compilation and analysis: FXH, KS, HH, CK Statistical analyses: MK Geographical data analysis: MW, WK Data collection on vaccination coverage: AE Data collection of infection sites in Styria (until 1983): WS Writing of manuscript: FXH, KS Revision and approval of manuscript: all.

\section{References}

1. Vaccines against tick-borne encephalitis: WHO position paper. Wkly Epidemiol Rec. 2011;86(24):241-56. PMID:21661276

2. Simmonds P, Becher P, Collett MS, Gould EA, Heinz FX, Meyers G, et al. Family Flaviviridae. In: King AMQ, Lefkowitz E, Adams MJ,Carstens EB, editors. Virus Taxonomy IXth Report of the International Committee on Taxonomy of Viruses. San Diego: Elsevier Academic Press. 2011.

3. Lindquist L, Vapalahti O. Tick-borne encephalitis. Lancet. 2008;371(9627):1861-71. http://dx.doi.org/10.1016/S01406736(08)60800-4 PMID:18514730

4. Jääskeläinen $A E$, Sironen T, Murueva GB, Subbotina N, Alekseev AN, Castrén J, et al. Tick-borne encephalitis virus in ticks in Finland, Russian Karelia and Buryatia. J Gen Virol. 2010;91(Pt 11):2706-12. http://dx.doi.org/10.1099/ vir.0.023663-0 PMID:20660147

5. Jääskeläinen AE, Tikkakoski T, Uzcátegui NY, Alekseev AN, Vaheri A, Vapalahti O. Siberian subtype tickborne encephalitis virus, Finland. Emerg Infect Dis. 2006;12(10):1568-71. http:// dx.doi.org/10.3201/eid1210.060320 PMID:17176574

6. Heinz FX, Stiasny K, Holzmann H, Grgic-Vitek M, Kriz B, Essl A, et al. Vaccination and tick-borne encephalitis, central Europe. Emerg Infect Dis. 2013;19(1):69-76. http://dx.doi.org/10.3201/ eid1901.120458 PMID:23259984

7. Romanenko VV, Kovalev SY, Esiunina MS, Ankudinova AV. Tactics and strategy of vaccine prevention of tick-borne encephalitis in the Sverdlovsk region. TBE: New paradigms in a changing vaccination environment. 13th Meeting of the International Scientific Working Group on Tick-borne encephalitis (ISW-TBE); Vienna, Austria; February 3-4, 2011.

8. Randolph SE. Tick-borne disease systems emerge from the shadows: the beauty lies in molecular detail, the message in epidemiology. Parasitology. 2009;136(12):1403-13. http:// dx.doi.org/10.1017/So031182009005782 PMID:19366480

9. Zeman P, Benes C. Spatial distribution of a population at risk: an important factor for understanding the recent rise in tickborne diseases (Lyme borreliosis and tick-borne encephalitis in the (zech Republic). Ticks Tick Borne Dis. 2013;4(6):522-30. http://dx.doi.org/10.1016/j.ttbdis.2013.07.003 PMID:24139627

10. Zeman P. Objective assessment of risk maps of tick-borne encephalitis and Lyme borreliosis based on spatial patterns of located cases. Int J Epidemiol. 1997;26(5):1121-9. http://dx.doi. org/10.1093/ije/26.5.1121 PMID:9363536

11. Danielová V, Daniel M, Schwarzová L, Materna J, Rudenko $\mathrm{N}$, Golovchenko M, et al. Integration of a tick-borne encephalitis virus and Borrelia burgdorferi sensu lato into mountain ecosystems, following a shift in the altitudinal limit of distribution of their vector, Ixodes ricinus (Krkonose mountains, Czech Republic). Vector Borne Zoonotic Dis. 2010;10(3):223-30. http://dx.doi.org/10.1089/vbz.2009.0020 PMID:19492952

12. Randolph SE. The shifting landscape of tick-borne zoonoses: tick-borne encephalitis and Lyme borreliosis in Europe. Philos Trans R Soc Lond B Biol Sci. 2001;356(1411):1045-56. http:// dx.doi.org/10.1098/rstb.2001.0893 PMID:11516382

13. Schuler M, Zimmermann H, Altpeter E, Heininger U. Epidemiology of tick-borne encephalitis in Switzerland, 2005 to 2011. Euro Surveill. 2014;19(13):20756. http://dx.doi. org/10.2807/1560-7917.ES2014.19.13.20756 PMID:24721541

14. Donoso Mantke O, Escadafal C, Niedrig M, Pfeffer M, Working Group For Tick-Borne Encephalitis Virus. Tickborne encephalitis in Europe, 2007 to 2009. Euro Surveill. 2011;16(39):19976. PMID:21968423

15. Amicizia D, Domnich A, Panatto D, Lai PL, Cristina ML, Avio $U$, et al. Epidemiology of tick-borne encephalitis (TBE) in Europe and its prevention by available vaccines. Hum Vaccin Immunother. 2013;9(5):1163-71. http://dx.doi.org/10.4161/ hv.23802 PMID:23377671

16. Randolph SE; EDEN-TBD sub-project team. Human activities predominate in determining changing incidence of tick-borne encephalitis in Europe. Euro Surveill. 2010;15(27):24-31. PMID:20630144 
17. Gray JS, Dautel H, Estrada-Pena A, Kahl O,Lindgren E. Effects of climate change on ticks and tick-borne diseases in europe. Interdiscip Perspect Infect Dis. 2009;593232.

18. Sumilo D, Asokliene L, Bormane A, Vasilenko V, Golovljova I, Randolph SE. Climate change cannot explain the upsurge of tick-borne encephalitis in the Baltics. PLoS ONE. 2007;2(6):e50o. http://dx.doi.org/10.1371/journal. pone.0000500 PMID:17551580

19. Zeman P, Pazdiora P, Benes C. Spatio-temporal variation of tick-borne encephalitis (TBE) incidence in the Czech Republic is the current explanation of the disease's rise satisfactory? Ticks Tick Borne Dis. 2010;1(3):129-40. http://dx.doi. org/10.1016/j.ttbdis.2010.05.003 PMID:21771520

20. Skarpaas T, Ljøstad U, Sundøy A. First human cases of tickborne encephalitis, Norway. Emerg Infect Dis. 2004;10(12):2241-3. http://dx.doi.org/10.3201/eid1012.040598 PMID:15663873

21. Jaenson TG, Hjertqvist M, Bergström T, Lundkvist A. Why is tick-borne encephalitis increasing? A review of the key factors causing the increasing incidence of human TBE in Sweden. Parasit Vectors. 2012;5(1):184. http://dx.doi.org/10.1186/17563305-5-184 PMID:22937961

22. Johan F, Asa L, Rolf A, Barbro C, Ingvar E, Mats H, et al. Tick-borne encephalitis (TBE) in Skåne, southern Sweden: A new TBE endemic region? Scand J Infect Dis. 2006;38(9):8004. http://dx.doi.org/10.1080/00365540600664068 PMID:16938735

23. Jääskeläinen $A E$, Tonteri $E$, Sironen $T$, Pakarinen L, Vaheri $A$, Vapalahti O. European subtype tick-borne encephalitis virus in Ixodes persulcatus ticks. Emerg Infect Dis. 2011;17(2):323-5. http://dx.doi.org/10.3201/eid1702.101487 PMID:21291624

24. Fomsgaard A, Christiansen C, Bodker R. First identification of tick-borne encephalitis in Denmark outside of Bornholm, August 2009. Euro Surveill. 2009;14(36):19325. PMID:19758543

25. Rieille N, Bally F,Peter O. [Tick-borne encephalitis: first autochtonous case and epidemiological surveillance in canton Valais, Switzerland]. Rev Med Suisse. 2012;8(357):1916-8, 1920. French.

26. Danielová V, Kliegrová S, Daniel M, Benes C. Influence of climate warming on tickborne encephalitis expansion to higher altitudes over the last decade (1997-2006) in the Highland Region (Czech Republic). Cent Eur J Public Health. 2008;16(1):411. PMID:18459472

27. Lukan M, Bullova E, Petko B. Climate warming and tick-borne encephalitis, Slovakia. Emerg Infect Dis. 2010;16(3):524-6. http://dx.doi.org/10.3201/eid1603.081364 PMID:20202437

28. Hasle G. Transport of ixodid ticks and tick-borne pathogens by migratory birds. Front Cell Infect Microbiol. 2013;3:48. http:// dx.doi.org/10.3389/fcimb.2013.00048 PMID:24058903

29. Waldenström J, Lundkvist A, Falk KI, Garpmo U, Bergström S, Lindegren $\mathrm{G}$, et al. Migrating birds and tickborne encephalitis virus. Emerg Infect Dis. 2007;13(8):1215-8. http://dx.doi. org/10.3201/eid1308.061416 PMID:17953095

30. Ernek E, Kozuch O, Lichard M, Nosek J. The role of birds in the circulation of tick-borne encephalitis virus in the Tribec region. Acta Virol. 1968;12(5):468-70. PMID:4386641

31. Pfeffer M, Dobler G. Emergence of zoonotic arboviruses by animal trade and migration. Parasit Vectors. 2010;3(1):35. http://dx.doi.org/10.1186/1756-3305-3-35 PMID:20377873

32. Gäumann R, Mühlemann K, Strasser M, Beuret CM. Highthroughput procedure for tick surveys of tick-borne encephalitis virus and its application in a national surveillance study in Switzerland. Appl Environ Microbiol. 2010;76(13):42419. http://dx.doi.org/10.1128/AEM.00391-10 PMID:20453126

33. Weidmann M, Frey S, Freire CC, Essbauer S, Růžek D, Klempa $B$, et al. Molecular phylogeography of tick-borne encephalitis virus in central Europe. J Gen Virol. 2013;94(Pt 9):2129-39. http://dx.doi.org/10.1099/vir.0.054478-o PMID:23784447

34. Randolph SE. Transmission of tick-borne pathogens between co-feeding ticks: Milan Labuda's enduring paradigm. Ticks Tick Borne Dis. 2011;2(4):179-82. http://dx.doi.org/10.1016/j. ttbdis.2011.07.004 PMID:22108009

35. Schneider F, Jelenik Z, Ferenczi E, Melles M, Zoldi V. TBE Epidemiology: Country Hungary. TBE - a Notifiable Disease 15 th Meeting of the International Scientific Working Group on Tick-borne encephalitis (ISW-TBE); Vienna, Austria; January 31-February 1, 2013. Poster presentation.

36. Kollaritsch H, Chmelík V, Dontsenko I, Grzeszczuk A, Kondrusik M, Usonis V, et al. The current perspective on tick-borne encephalitis awareness and prevention in six Central and Eastern European countries: report from a meeting of experts convened to discuss TBE in their region. Vaccine. 2011;29(28):4556-64. http://dx.doi.org/10.1016/j. vaccine.2011.04.061 PMID:21549781
37. Population Censuses, Register-based Census, Register-based Labour Market Statistics. Total population. Vienna: Statistics Austria. [Accessed: 22 Dec 2013]. Available from: http:// www.statistik.at/web_en/statistics/population/population censuses register based_census_register based labour market statistics/totaL population/index.html 